\title{
The Impact of Referee Training: Reflections on the Reduction of Home Advantage in Association Football.
}

\author{
Abstract \\ The effect of increased development and professionalisation in elite Association \\ Football referee training and the relationship with reduced home advantage in the \\ English professional leagues were examined. The central aim was to chart the evolution \\ of referee training, and how these developments in referee training have assisted in \\ reducing home advantage. Interviews were conducted with elite and ex-elite referees, \\ as well as those involved in the management, training and administration of elite \\ referees in order to identify more recent adaptations to elite referee training and further \\ explain the relationship between training and the reduction in home advantage. \\ Findings indicate training and support is pronounced within elite refereeing has \\ developed appreciably over time, and has contributed significantly to an increase in \\ performance, decision making correctness and subsequent decline in home advantage.
}

Keywords: Training, Team Sport, Sport Psychology, History, Performance. 


\section{Introduction}

There is a body of research that has examined the existence of home advantage (HA) in various team sports such as baseball, ice hockey, American football and also Association Football (soccer). ${ }^{1}$ The standard model $^{2}$ offers a framework for the study of HA with an emphasis placed on the examination of the causal processes that connect game locations factors to performance outcomes. ${ }^{3}$ The standard model proposes that there are four factors that may influence HA, namely travel fatigue, ${ }^{4}$ familiarity with playing surroundings, ${ }^{5}$ competition rules that may favour the home team, and crowd effects on players, officials or both. ${ }^{6}$ Specific to the latter factor, research has previously suggested that audience support and associated psychological pressure can influence the decision making process of officials. ${ }^{7}$

Recent research observations have begun to highlight a decline of HA at lower levels of competition (divisions with smaller crowds). Nevill, Webb, and Watts ${ }^{8}$ argued that crowd support in particular may have less influence over referee decisions. Moreover, these researchers identified that physiological and psychological elements included in the training of referees may have resulted in the greater resilience of referees to crowd influence. To this end, Nevill and colleagues postulated that the importance associated with the improvements in referee training were more influential in terms of the reduction of HA than had previously been accepted. Therefore, further to previously established influences on $\mathrm{HA}^{9}{ }^{9}$ the aim of this article is to examine the impact that improvements and advancements in the training of referees may have had on a decrease in HA. In order to address this aim, we implement a novel methodological approach for the study of referee training by bringing together complementary lines of inquiry drawn from social science, historical enquiry and sport psychology. ${ }^{10}$ 


\section{Review of Referee Training Literature}

In order to further explain the decline in HA, consideration of the way referees have been trained and prepared over time can assist in contextualising this concept. The pertinent events, milestones and occurrences derived from a variety of literature (including scientific publications, meeting minutes, industry publications and newspaper reports) provides a unique body of evidence to examine the changes that have taken place in the way that referees have been trained over a prolonged period of time. In the following sections, we begin by considering published literature across three different periods of referee training: (i) 1886 - 1945; (ii) post-world war (WW) 2 until the 1980s; and (iii) 1980s until the present day.

\section{Referee training: 1886-1945}

The first guidance for umpires and referees was issued by the football association (FA) via a memorandum in $1886^{11}$ with the second generation of the rules and instructions for referees following in 1896 through the production of 'the Referees' Chart'. ${ }^{12}$ FA Referees' Committee minutes in 1913 asked for a uniform approach towards the training of referees with the Conference of County and District Association Referees, Secretaries and Representatives unanimously resolving that there was, ' $\ldots$ the necessity of investigating and considering the present methods adopted by the various affiliated Bodies for the training and promotion of Referees with a view to formulating a definite scheme for adoption'. ${ }^{13}$ The Referees' Committee rejected the notion, arguing that ' ... it was not desirable to formulate a definite scheme'. ${ }^{14}$

Further to consideration of training procedures within the UK, the $10^{\text {th }}$ annual Fédération Internationale de Football Association (FIFA) congress held in Copenhagen from $31^{\text {st }}$ May - 1st June 1913 featured discussions on refereeing, including a motion proposing a 
refereeing specific conference. This was met with disagreement, in particularly from the English representative who believed that ' ... in England a referees union had been formed [but] the conditions were no better than 25 years earlier, many referees don't even carefully read the Laws of the Game'. ${ }^{15}$ Referees, and their training, were an afterthought in the game at this point, yet there was a clear understanding, within the international game, if not in England, that refereeing was something with which governing bodies should be concerned. As the game moved into the 1920s, 1930s and 1940s the literature is particularly sparse regarding the training of referees. Despite the paucity of literature, there were still some pertinent developments that occurred during this time period, such as FIFA establishing a Rules and Regulations committee in $1927 .^{16}$

At the onset of WW2 in 1939, arguments were being made for adaptations to the rules of the game, such as amendments to the off-side law, with the aim of increasing the number of breakaways, and attacks from opposing teams. This consequently meant that referees were being left 30 to 40 yards away from goals that they were either allowing or disallowing ${ }^{17}$ and in turn, led to questions over the fitness of the referees and their training.

\section{Refereeing training, development and assessment post-WW2}

After WW2 the FA was urging the Referees' Association (RA) to focus on the recruitment of referees and also stated that it was the ' ... duty of the Association to find [these referees] and train them'. ${ }^{18}$ The FA organised the first of a series of conferences which were designed to study the question of refereeing ${ }^{19}$ producing an illustrated version of the Laws of the Game by 1948. Furthermore, FIFA had begun to organise International Conferences and a Conference on Refereeing was held in London in 1948, organised by the FA in conjunction with FIFA. ${ }^{20}$ 
Towards the end of the 1950s, there had been significant developments regarding referee training. A FIFA organised Referee Instructor course took place in Macolin, attended by an FA delegate ${ }^{21}$ and an inaugural mention is evident in the FA minutes ${ }^{22}$ regarding the first of what were to become annual courses for referee instructors, beginning in 1958. These courses meant that referees were being guided by instructors that were themselves being trained for the first time to deliver educational content to referees and by the late $1950 \mathrm{~s}$, the FA was giving explicit direction to referees, in respect of their game management, through these trained instructors. ${ }^{23}$

A report on referees' courses/conferences in 1957 evidenced that there were FA Regional Referees' Conferences, an FA Referees' Course at Bisham Abbey from $28^{\text {th }}$ July$2^{\text {nd }}$ August, a French FA Summer School for Referees from $5^{\text {th }}-7^{\text {th }}$ July and a FIFA Referees' Course at Macolin from $5^{\text {th }}-7^{\text {th }}$ August. ${ }^{24}$ A further referee's course was organised at Bisham Abbey in 1958, utilising BBC film footage of matches to assist instruction, and was intended for those that wanted to instruct new referee candidates. ${ }^{25}$ Alongside these courses, the RA was emphasising the importance of attendance at physical training and instructional meetings. ${ }^{26}$

Despite these instructional courses, in 1968, referees were still undergoing minimal formal training. ${ }^{27}$ The publication of the 'Chester Report' in 1968 recommended that the Football League should appoint a director of referees, 'responsible for the training and selection of match officials' ${ }^{28}$ The summer of 1969 saw a further course for referee instructors administered by the $\mathrm{FA}^{29}$ Also taking place in 1969 was the first UEFA training course for referees in Florence. ${ }^{30}$ 
As refereeing entered the 1970 s, there was evidence that physical training was becoming a greater consideration with sections of 'The Football Referee' in 1973 directly related to the fitness of referees. ${ }^{31}$

This guidance that was beginning to become more evident can be linked to the start of a steeper decline in HA at around the same time in the 1970s (Figure 1). Referees were starting to understand the need to be physically fit and able to keep up with the game, but the information that would enable them to do this was not as readily available. ${ }^{32}$

Figure 1 near here.

There was still work that needed to be undertaken related to referee training. The FA, through their Referee Secretary, Reg Paine argued ‘ ... that the methods of training referees, and the updating of their outlook, have not progressed as they should have done' ${ }^{33}$ Nevertheless, there were further developments internationally relating to the fitness of referees, at the elite level, such as the introduction of the FIFA fitness test and minimum standards of fitness for FIFA referees in 1974 after concerns over the level of fitness of the referees that officiated at the 1974 World Cup. ${ }^{34}$

In addition to the improvements that have been identified in referee training, there were further indications, through the assessment of referees in professional football and in particular the matches that they officiated in the Football League, that demonstrated a desire for training to develop and also for some consideration of the impact and perceived advantage to the team that was playing at home. For example, referee assessment reports from Preston North End matches demonstrate that there were comments from clubs which stated that referees favoured the home team. 
A report from a Preston North End match in 1958 (figure 2) states that the '...official along with his two linesmen showed marked tendencies to favour the home team.' At this point referee assessments were still reliant on club marks predominantly, although there was little chance for referees at the time to act or implement any of the feedback that they were given from the clubs. In an attempt to improve club feedback on the performance of the referee the marking sheets were changed from the 0-4 scale which had been in operation for almost 40 years, to the $0-10$ marking scale in the $1970-71$ season.

Figure 2 near here

It was hoped that the introduction of the 10 point marking scale would increase the quality of referee feedback and also the comments that were included as part of the marking sheet. Figure 3 shows a referee assessment report from a Preston North End match in 1971, with the report identifying that Preston North End viewed the referee as something of a 'homer' who also 'lacked control'. Whether the quality of information for referees, and those in managerial roles at this time improved is debateable, although it is clear that through the assessment system referees were seen to be favouring the home side, and therefore it is reasonable to suggest that an increase in the quality of physical and technical training would begin to target and address these perceptions.

Figure 3 near here

\section{Developments in refereeing from the $1980 \mathrm{~s}$}

The requirement for referees to be physically ready for matches was being shared with a wider refereeing population by 1985 . Instruction through 'The Football Referee' directing referees towards competent and specific warm-ups prior to matches from UEFA 
instructors was printed following a UEFA course for 'Top-class referees' in Hungary in August $1982 .{ }^{35} 1988$ saw guidance published regarding fitness and nutrition, ${ }^{36}$ with 1990 also seeing information released concerning marking guidelines to which assessors adhered related to the fitness of a Football League referee, and also some of the recommendations that FIFA expected to be followed. ${ }^{37}$

Despite this increase in fitness related information available for referees, by 1991 elite referee training was still something that was self-governed, and therefore was reliant on the diligence and dedication of the individual referee to an extent. ${ }^{38}$ In the UK, further developments in referee training were particularly prevalent as the twenty first century began. The appointment of sports scientists, sports psychologists and referee coaches by the Professional Game Match Officials Limited (PGMOL) in 2001, as well as the introduction of Prozone, which provided technical information on referees training and performance in 2002. Leading to present day, a Training and Development Manager now works for the PGMOL to co-ordinate the development programme for all elite match officials, demonstrate the intention to embrace and adopt scientific and technological advancements in order to keep pace with the wider game. ${ }^{39}$

With the above in mind, the purpose of this study is to further evidence the increased provision and professionalisation of training as a crucial factor in the reduction of HA in the English professional football leagues, specifically the Premier League. Complementary to the contextualisation of the historical foundation of referee training described that is grounded in 'sociology', we implement a qualitative content analysis methodological framework based upon semi-structured interviews of current elite level referees, trainers and administrators. 


\section{Methods}

\section{Participants}

Participants were recruited via purposive sampling, involving the selection and involvement of a particular societal group or sample because of their unique position related to the research. ${ }^{40}$ The 18 participants were all from England. All participants were working in the field of professional football and elite level (Premier League) refereeing as current elite level referees, ex-elite level referees, referee assessors, referee coaches, managers and administrators from bodies that manage and are associated to refereeing. All participants consented to participate in the research following favourable institutional ethical opinion after protocol submission to the requisite ethics committee. Respondents were assured of anonymity when they were contacted and therefore pseudonyms have been utilised to protect the identity of the respondents, participant ages and the amount of time they have officiated and worked in refereeing are also not disclosed in order to fully protect anonymity.

\section{Interview guide}

A semi-structured interview approach was adopted where an identical set of questions was employed. This ensured that there was an element of structure to each of the interviews conducted; however, the ordering of the questions was dependent on the responses that were given by each participant, where issues raised were explored by the interviewer (the lead author). Discussions naturally varied during each interview, due to the semi structured nature of the interviews and the differing responses from the respondents.

Interviews were conducted face-to-face and over the phone, this was decided by the participant. The interviews were recorded in their entirety (no more than 75 minutes in 
duration) and transcribed verbatim. Participants were given information regarding the research, by hard copy, e mail or verbally, prior to being interviewed.

\section{Data analysis}

Having transcribed each of the interviews, inductive content analysis was employed as a means of analysing the themes generated through the large amount of data that was gathered $^{41}$. Furthermore, content analysis affords the researcher a coherent manner of being presented to colleagues for peer dissemination; this type of dissemination can lead to verification of the data analysis process and give the research added 'trustworthiness' through the concept of "critical friends'. ${ }^{42}$ This can not only verify and inform the data collection and analysis that has already occurred but also assist the researcher in terms of support, and suggestions that otherwise may not have been considered.

After the initial higher and lower order themes had been identified, the transcribed interview quotations were read and re-read by 2 academics trained in qualitative research. Each researcher then viewed the higher and lower order themes and independently identified and verified the phrases, quotations and themes that they had been asked to consider. These themes and quotations were independently grouped, compared to the initial themes that had been generated and then placed into general dimensions above which no general meaning could be identified (Figure 4).

Figure 4 near here 


\section{Results and discussion}

\section{Changes in training and support from the 1980s}

The participants described their perception of the training and support they had received since being involved with refereeing. Initially it is useful to see the transformation in the approach to training respondents have identified. Referees have suggested that the particular lower order themes, such as physical training, technical training and psychological training (Figure 2), have all contributed to improvements in their training and performance and therefore a reduction in HA. Adam, an elite/ex elite referee, recalls the changes in training over time compared to the training that referees currently receive, 'From when I started back in 1988 to now, I think referees probably get 100 times more support and have a lot more information and guidance than they've ever had'.

Adam's comments support the historical training developments in refereeing as a means to explain the reduction in HA outlined in this paper. The argument can be made that these changes have elevated refereeing towards a more professionalised mindset, 'I think again since I retired ... even that has become more and more professional with far more analysis of games to help match officials' progress and develop' (Barry, referee management and training). The professionalisation of training and analysis of matches that Barry discusses can be linked to the reduction in HA in the English leagues ${ }^{43}$. Respondents made several references to the improvement that they had witnessed in the training that referees receive.

\section{Current referee training}

The area of referee training that has seen the most rapid development concerns physical fitness. The move to full time referees at the elite level in England has certainly helped this improvement, ${ }^{44}$ although this has been assisted with a willingness to adapt and 
embrace recent advancements in the area of physiology. ${ }^{45}$ This willingness to embrace change has, in turn, led to increased levels of fitness within refereeing, 'I don't think the fitness levels of referees are a problem in the slightest; they might have been in years gone by but I think we're at the level now where we have taken massive strides forwards' (Aaron, elite/ex elite referee).

It is clear that referees have embraced enhanced levels of support. ${ }^{46}$ Training is now heavily loaded to ensure that referees are fair, unbiased and confident in their decision making, potentially as a consequence in the improvement of physical fitness. Because of the increase in referee fitness and therefore the position a referee takes on the field that facilitates accurate decision making, the impact of extraneous elements such as crowd noise on their decision making have been reduced, if not entirely eradicated, and as a consequence we can see an associated reduction in HA. Some reasons for this improvement can be traced to the introduction of full time referees, the employment of full time sports scientists (since 2001) and the introduction of the Prozone performance analysis system, used by PGMOL since 2002.

The support that referees at the elite level now receive is substantially improved. Referees at the elite level, and further down the development pathway, now have designated referee coaches that work with them and support their training, 'in the Premier League, even at semi-professional level, the majority have got coaches' (Boris, ex elite referee and referee coach). Such initiatives have contributed to the reduction in HA that has been observed since WW2. The professionalisation of refereeing has extended from physical training to the use of video to review decision making. The adaption of these practices has assisted in the reduction in HA and in turn fostered a climate of professionalism: 
'We have a video review... we'll look at some topical trends; we'll discuss in smaller groups and then feedback in plenary and a big group. We will also look at the weekend's action and highlight some good practice or maybe some areas that could have been handled better'.

(Aaron, elite/ex elite referee)

Analysis of decisions made within the elite referee group ensures that good practice is encouraged. ${ }^{47}$ These areas of discussion can be worked upon by the referee coaches and can also be given attention in the referee assessors' report, 'If there is something, say positioning, then yes something will go in the debrief, something will go in a written assessment....and the referees' coach will also see that and they will be able to work on that' (Barry, referee assessor).

The addition of the referee coach is an advancement that is designed to assist referee learning. The position is particularly important due to the nature of the use of video and the group sessions that have been outlined by the interview respondents. The referee coaches work with the elite referees and identify areas of development specific to individual referees. Therefore the introduction of the referee coaches is another step towards the improved training of referees at the elite level and can help explain the further reduction in HA from the 1980s to the present day.

The PGMOL have introduced other roles such as the training manager, which demonstrates further evidence of the improved training afforded to referees, 'we have a dedicated training manager who provides our theoretical training ... we also have an extranet site which shows us clips and presentations' (Aidan, elite/ex elite referee). When this is related back to the reduction in HA, one can begin to see how the changes in referee training and the support that elite referees have received over time, manifests themselves in improved decision making and a subsequent reduction in HA. 


\section{Preparation and Premier League grounds}

The increase in the professionalisation of training has, in turn, led to a reduction in HA in English football. However, training has also been focused on improving referee performance and decision making at 'big' stadiums or in the 'big' matches, although Fred indicated that it is also a result of the quality of the match official in question:

'Referees are human beings ... the best ones are least influenced and are only influenced by what they see, not by what is going on around them ... the home crowd, the score in the match, a previous decision, referees can get influenced by a number of factors ... but the best won't be.'

(Brian, referee management and training)

The suggestion is that referees can be influenced, but as referees have improved through innovations and improvements in training, the 'best' referees, or those that officiate in the Premier League or within professional football are perceived to be less likely to be influenced by factors such as the 'home crowd'. The influence of stadiums, larger crowds and HA is something that is recognised as a factor that referees need to control and be aware of in order to improve performance and decision making. Part of the training for elite referees is being able to perform and act in the same way irrespective of surroundings, although clearly the training is important to ensure that referees control aspects such as nerves and crowd size in order to perform effectively:

\footnotetext{
'It was more intimidating when you went to Anfield or Old Trafford than when you went to Coventry or Aston Villa, but you don't treat it any different ... it's a little bit different when you have 65,000 people against 25,000 but once you are actually out there and you've started you're trying to shut that off.'
} 
(Ben, referee management and training)

Referees are now trained, not only physically and technically, but also in terms of their preparation prior to matches to ensure that when they step onto the pitch they do not distinguish between the size or magnitude of the clubs in question, or whether these teams are at home or away. Barry (referee management and training) stressed that when a referee is on the pitch they do not consider the size of the game because they are trained and taught to approach every match in the same way:

' ... because when you're out on the field of play it's all yellows and blues you don't think "oh I can't give that decision because it's Manchester United". You are not even thinking about that. No, the size of game I don't think has any bearing, particularly because the approach to every game should now be standard.'

This sentiment was supported by Adam (elite /ex elite referee) who agreed that '.. the message to get out to all referees is that we should treat every game the same.' Evidently, this is something, alongside other aspects of training which elite referees have also been trained to improve.

The method that the elite refereeing authorities such as the PGMOL and the FA take when considering referee training, and also the placement of referees at matches, could also be a factor in the decline of HA over time. For example, historically referees have been asked to continue to referee a certain team even if it is perceived that they have had a poor match which has contained errors in decision making. However, this process is now more professionalised with a degree of strategy employed in the placement of referees: 
'Going back to my very early years, I could referee a Football League game and if that game didn't go particularly well, for whatever reason, you used to get sent back there in a couple of weeks and you kept going back there until you did have a good game... but of course now you've got a body of professional referees.'

(Brian, referee management and training)

It appears that alongside the changes and advancements that have been documented and discussed related to referees' physical training, the support networks have seen investment and structure with the introduction of Referee Coaches, introduced in order to facilitate and encourage referee development and learning. Furthermore, referee managers have been considering referee preparation prior to matches, as well as performance during matches, in order to improve decision making and as a consequence, also improve HA.

\section{General summary}

The central aim of this paper has been to examine the development, improvement and professionalisation of referee training in order to further explain and understand the reported reduction in HA in the English professional football leagues. ${ }^{48}$ The growth of refereeing since 1886 to the present day has been considered, with specific reference to the influence that changes in training have had on the referee, and therefore, the impact that these changes have had on the reduction in HA. The game has changed incontrovertibly since the end of WW2, with refereeing at the elite level in today's game of Association Football never encountering such interest from those within football, the media and fans. ${ }^{49}$ The decisions that a referee makes are often subjected to persistent scrutiny, utilising a variety of cameras that are located throughout the stadium. The pressure for referees to get the decision right is something which those in managerial positions are aware of, and adaptations in training have been undertaken with this specific focus. 
Given the changes in referee training, especially since the inception of the Premier League in 1991, and more recently the introduction of professional or 'full-time' referees in England, but also over time, there has been a marked increase in the level of support and training that referees receive. This support network is pronounced within elite refereeing, and has contributed significantly to an increase in refereeing performance, increase in decision making accuracy and therefore a likely reduction in HA. From this view, the current paper postulated that the increase in the quality and availability of training for referees over time has been the significant contributory factor to a reduction in HA.

As highlighted at the outset of this article, the standard model of HA proposes that there are four factors that may influence HA, namely travel fatigue ${ }^{50}$ familiarity with playing surroundings, ${ }^{51}$ competition rules that may favour the home team, and crowd effects on players, officials or both. ${ }^{52}$ While the present results indicate that the HA may have lessened due to a decreased affect on officials, it is also plausible that the advancements in the preparation and training of players may have led to a decrease in HA. That is, the documented improvements in the training of officials as highlighted in this paper are likely to be mirrored by improvements in the training of players, to help teams prepare both tactically and psychologically. ${ }^{53}$ It follows that future work is required to better understand the other causal-processes may impact upon the prevalence of HA that go beyond the performance of officials. $^{54}$

\section{Notes}


${ }^{1}$ Courneya and Carron, 'The Home Advantage'; Koyama and Reade, 'Playing like the Home'; Nevill and Holder, 'Home Advantage in Sport'; Pollard, 'Home Advantage in Soccer'; Schwartz and Barsky,'The Home Advantage'.

${ }^{2}$ Courneya and Carron, 'The Home Advantage'.

${ }^{3}$ Allen and Jones, 'The "Home Advantage".

${ }^{4}$ Pollard, 'Home Advantage in Soccer'; Pollard and Pollard, 'Long Term Trends'.

${ }^{5}$ Pollard and Pollard, 'Long Term Trends'.

${ }^{6}$ Nevill, Balmer and Williams, 'The Influence'; Nevill, Newell and Gale, 'Factors Associated'.

${ }^{7}$ Downward and Jones, 'Effects of Crowd Size'.

${ }^{8}$ Nevill, Webb and Watts, 'Improved Training'.

${ }^{9}$ For a review, see Allen and Jones, 'The "Home Advantage"'.

${ }^{10}$ cf. Uehara, Button, Falcous and Davids, 'Contextualised Skill Acquisition Research'.

${ }^{11}$ Green, The History; Witty, The Organization of Referees.

${ }^{12}$ Witty, 'The Organization of Referees'.

${ }^{13}$ FA Referees' Committee minutes, July 05, 1913.

${ }^{14}$ FA Referees Committee minutes, December 01, 1913.

${ }^{15}$ FIFA Annual Congress minutes, June 01, 1913.

${ }^{16}$ Rous, Football Worlds.

${ }^{17}$ Sharpe, 40 Years in Football.

${ }^{18}$ Cheltenham Conference, 3.

${ }^{19}$ Lovick, The "Middle” Man

${ }^{20}$ Green, The History.

${ }^{21}$ FA Referees' Committee minutes, May 03, 1957.

${ }^{22}$ FA Referees' Committee minutes, December 09, 1957.

${ }^{23}$ Webb, 'The Emergence of Training'. 
${ }^{24}$ FA Referees' Committee minutes, May 03, 1957; FA Referees' Committee minutes, September 23, 1957.

${ }^{25}$ Rae, Teaching the Teachers; Webb, The Emergence of Training.

26 'Physical Training', 6

${ }^{27}$ Hopcraft, The Football Man.

${ }^{28}$ Inglis, League Football.

${ }^{29}$ FA Instructional Committee minutes, April 22, 1970.

${ }^{30}$ FA Referees' Committee minutes, April 15, 1970.

${ }^{31}$ Smith, Suggested Physical Fitness, 19-20.

32 'Physical training for referees', 16.

${ }^{33}$ Paine, Why we don't want, 14.

${ }^{34}$ Evans and Bellion, The Art of Refereeing.

${ }^{35}$ Hevizi and Szilagyi, How a referee.

${ }^{36}$ Martin, Fitness and Diet.

37 'How assessors assess fitness'.

38 'George Courtney speaks at north Middlesex'.

${ }^{39}$ Nevill et al., 'Improved Training'.

${ }^{40}$ Byrne, 'Qualitative Interviewing'; Schutt, Investigating the Social World.

${ }^{41}$ Biddle, Markland, Gilbourne, Chatzisarantis, and Sparkes, 'Research Methods in Sport'.

${ }^{42}$ Faulkner and Sparkes, 'Exercise as Therapy'.

${ }^{43}$ see Nevill et al., 'Improved Training'.

44 'Football referees turn professional'.

${ }^{45}$ Castagna, Abt and D'Ottavio, 'Physiological Aspects of Soccer'; Castagna, Abt and D'Ottavio, 'Activity Profile'; Weston, Bird, Helsen, Nevill and Castagna, 'The Effect'.

${ }^{46}$ Weston, 'Match Performance'. 
${ }^{47}$ see also Helsen and Bultynck, 'Physical and Perceptual'; Lane, Nevill, Ahmad and Balmer, 'Soccer Referee Decision Making'.

${ }^{48}$ Nevill et al., 'Improved Training'.

${ }^{49}$ Mason and Lovell, 'Attitudes, Expectations and Demands'.

${ }^{50}$ Pollard, 'Home Advantage in Soccer'; Pollard and Pollard, 'Long Term Trends'.

${ }^{51}$ Pollard and Pollard, 'Long Term Trends'.

${ }^{52}$ Nevill, Balmer and Williams, 'The Influence'; Nevill, Newell and Gale, 'Factors Associated'.

${ }^{53}$ Thelwell, Greenlees and Weston, 'Using Psychological Skills Training'.

${ }^{54}$ See Allen and Jones, 'The "Home Advantage"”.

\section{References}

Allen, M. S., and M. V. Jones. 'The "Home Advantage" in athletic competitions'. Current Directions in Psychological Science 23, no. 1 (2014): 48-53.

BBC Sport. 'Football Referees Turn Professional'. BBC Sport, June 13, 2001, http://news. bbc.co.uk/sport1/hi/football/1386841.stm (accessed December 16, 2013).

Biddle, S. J. H., D. Markland, D. Gilbourne, N. L. D. Chatzisarantis, and A. A. Sparkes. (2001). 'Research methods in sport and exercise psychology: Quantitative and qualitative issues'. Journal of Sports Science 19, no. 10 (2001): 777-809.

Byrne, B. 'Qualitative interviewing'. In Researching society and culture, $2^{\text {nd }}$ ed., ed. C. Searle, 179-192, London: Sage, 2004.

Castagna, C., G.Abt, and S. D’Ottavio. 'Physiological aspects of soccer referee performance and training'. Sports Medicine 37, no. 7 (2007): 625-646. 
Castagna, C., G. Abt, G, and S. D'Ottavio. 'Activity profile of international-level soccer referees during competitive matches.' Journal of Strength and Conditioning Research 18, no. 3 (2004): 486-490.

'Cheltenham Conference'. The Football Referee 4. Transitory Period, September 1946.

Courneya, K. S., and A. V. Carron. 'The home advantage in sport competitions: a literature review'. Journal of Sport and Exercise Psychology 14 (1992): 13-27.

Downward, P., and M. Jones. 'Effects of crowd size on referee decisions: Analysis of the FA cup'. Journal of Sports Sciences, 25 (2007): 1541-1545.

Evans, R., and E. Bellion. The art of refereeing: Techniques and advice for every soccer referee. London: A \& C Black, 2005.

Faulkner, G., and A. Sparkes. 'Exercise as therapy for schizophrenia: An ethnographic study'. Journal of Sport and Exercise Psychology 21 (1999): 52-69.

'George Courtney speaks at north Middlesex’. The Football Referee 7, March 1991.

Green, G. The History of The Football Association. London: Naldrett Press, 1953.

Helsen, W. and J. B. Bultynck. 'Physical and perceptual-cognitive demands of top-class refereeing in association football'. Journal of Sports Sciences 22, no. 2 (2004): 179-189.

Hevizi, O., and G. Szilagyi. How a referee should warm up. The Football Referee 5, January 1985.

Hopcraft, A. The football man: People and passions in soccer. London: Collins, 1968.

'How assessors assess fitness'. The Football Referee 2, October 1990.

Inglis, S. League football and the men who made it. London: Collins Willow, 1988.

'International Corner'. The Football Referee, August 1938. 
Koyama, M., and J. J. Reade. 'Playing like the home team: an economic investigation into home advantage in football'. The International Journal of Sports Finance 4, no. 1 (2009): 1641.

Lane, A. M., A. M. Nevill, N. S. Ahmad, and N. Balmer. 'Soccer referee decicion making: 'Shall I blow the whistle?' Journal of Sport Science and Medicine 5 (2006): 243-253.

Lovick, E. The "Middle” Man; Mainly For Referees But of Interest to All Followers of the Game. Bury St. Edmonds: Groom \& Son, 1963.

Martin, J. Fitness and diet. The Football Referee 6, February 1988.

Mason, C., and G. Lovell. 'Attitudes, expectations and demands of English Premier league association football referees'. Football Studies 3, no. 2 (2000): 88-102.

Nevill, A. M., N. J. Balmer, and A. M. Williams. 'The influence of crowd noise and experience upon refereeing decisions in football'. Psychology of Sport and Exercise 3 (2002): $261-272$

Nevill, A. M., and R. L. Holder. 'Home advantage in sport: an overview of studies on the advantage of playing at home'. Sports Medicine 28 (1999): 221-236.

Nevill, A. M., S. M. Newell, and S. Gale. 'Factors associated with home advantage in English and Scottish soccer matches'. Journal of Sports Sciences 14, no. 2 (1996): 181-186.

Nevill, A., T. Webb, and A. Watts. 'Improved training of football referees and the decline in home advantage post-WW2'. Psychology of Sport and Exercise 14 (2013): 220-227.

Paine, R. Why we don't want professional referees. The Football Referee, February 1973. 'Physical training and instructional meetings'. The Football Referee 3 (5). New Series, May 1957.

'Physical training for referees'. The Football Referees, December 1974. 
Pollard, R. 'Home advantage in soccer: a retrospective analysis'. Journal of Sports Sciences 4 (1986): 237-248.

Pollard, R., and G. Pollard. 'Long terms trends in home advantage in professional team sports in North America and England (1876-2003)'. Journal of Sports Sciences 23 (2005): 337-350. Rae, V. Teaching the teachers: Referee course at Bisham Abbey. The Football Referee 11 (11), November 1958.

Rous, S. Football worlds: A lifetime in sport. Newton Abbot: Readers Union, 1978.

Schutt, R. S. Investigating the social world: The process and practice of research. $6^{\text {th }}$ ed. London: Pine Forge Press, 2009.

Schwartz, B., and S. F. Barsky. The home advantage. Social Forces 55 (1977): 641-661.

Sharpe, I. 40 years in football. London: The Sportsmans Book club, 1954.

Smith, I. Suggested physical fitness test for referees. The Football Referee, August 1973.

Thelwell, R. C., I. A. Greenlees, and N. J. Weston. 'Using psychological skills training to develop soccer performance'. Journal of Applied Sport Psychology 18, no.3 (2006): 254-270. Uehara, L., C. Button, M. Falcous, and K. Davids. 'Contextualised skill acquisition research: a new framework to study the development of sport expertise'. Physical Education and Sport Pedagogy (2014). http://dx.doi.org/10.1080/17408989.2014.924495.

Webb, T. 'The emergence of training and assessment for referees in Association Football: Moving from the side-lines'. The International Journal of the History of Sport 31, no. 9 (2014): 1081-1097.

Weston, M. 'Match performance of soccer referees: The role of sport science'. Movement and Sport Sciences 87 (2015): 113-117. 
Weston, M., S. Bird, W. Helsen, A. Nevill, and C. Castagna. 'The effect of match standard and referee experience on the objective and subjective match workload of English premier league referees'. Journal of Science and Medicine in Sport 9, no. 3 (2006): 256-262..

Witty, J. R. 'The organization of referees'. In Association Football, Volume 1., ed. A. H. Fabian and G. Green, 197-202. London: The Caxton Publishing Company Ltd, 1960. 